\section{Validation of a food frequency questionnaire to assess the consumption of carotenoids, fruits and vegetables among adolescents: the method of triads}

\author{
Validação de um questionário de frequência \\ alimentar para avaliar o consumo de carotenóides, \\ frutas e hortaliças: o método das tríades
}

\begin{abstract}
${ }^{1}$ Faculdade de Saúde Pública, Universidade de São Paulo, São Paulo, Brasil.

Correspondence S. M. Voci Faculdade de Saúde Pública, Universidade de São Paulo. Av. Dr. Arnaldo 715, 2o andar, São Paulo, SP 01246-904, Brasil.

smvoci@usp.br
\end{abstract}

\section{Abstract}

The aim of this study was to validate the intake of carotenoids, fruits and vegetables estimated by the Food Frequency Questionnaire for Adolescents (FFQA) using the method of triads. Blood samples were collected from 80 elementary school adolescents to assess serum levels of $\beta$-carotene. Partial correlation coefficients ( $r$ ) were calculated between an estimated intake of carotenoids, fruits and vegetables and the serum levels of $\beta$-carotene. Validity coefficients were calculated using the method of triads. With the exception of carotenoids, partial $r$ from the food frequency questionnaire (FFQ) were greater than those of the 24-hour recall (24hR). The fruit/vegetable group showed the highest partial $r$ for the $F F Q$ $(r=0.235)$ and the $24 \mathrm{hR}(r=0.137)$. The highest validity coefficient was obtained for the vegetable group, as assessed by the FFQ ( $r=0.873)$. On average, the validity coefficient values for the $F F Q$ were greater than those obtained for the $24 \mathrm{hR}$ or the $\beta$-carotene serum levels. The FFQA is an accurate tool for estimating the intake of carotenoids, fruits and vegetables in this population group.

Food Consumption; Questionnaire; Adolescent; Validation Studies

\author{
Betzabeth Slater 1 \\ Carla Cristina Enes 1 \\ Rossana Verónica Mendoza López 1 \\ Nágila Raquel Teixeira Damasceno ${ }^{1}$ \\ Silvia Maria Voci 1
}

\section{Introduction}

The biggest challenge encountered in epidemiological studies that associate diet with chronic diseases has been the inaccuracy of dietary in formation collected using food frequency questionnaires (FFQ), 24-hour recalls (24hR) and food record 1 .

According to Freedman et al. 2 random errors in structured questionnaires are the principal cause of underestimating relative risk (RR) and the reduced statistical power of epidemiological studies. Furthermore, the tendency to overestimate or underestimate consumption can systematically distort the proportion of differences in the consumption of observed food groups ${ }^{3}$.

As a result of these errors, biochemical markers have been widely used both in validation studies (to assess the accuracy of traditional methods) and as a measure of intake, since any error presented is independent from the error inherent to traditional methods of evaluating dietary intake 4,5 .

Although there are few biochemical markers that possess the ideal characteristics of dietary markers, studies suggest that serum carotenoids are potential biomarkers for the intake of fruits and vegetables $6,7,8$. A review of the literature investigated whether the concentration of carotenoids in blood can serve as a biological marker for the intake of fruit and vegetables. The literature indicates an association between intake of 
fruit and vegetables and the concentration of carotenoids, especially $\alpha$-carotene and plasma total carotenoids 9 .

However, it is important to remember that serum concentrations of carotenoids are correlated with other factors, such as age, body mass index (BMI), triglycerides and cholesterol serum concentrations. These potentially confounding factors justify the necessity of validating this method as well as the more traditional methods 10 .

According to Hunter 5 serum concentrations of carotenoids depend not only on dietary intake of these components, but also on other concomitantly ingested nutrients. Fats and other liposoluble components favor the absorption of carotenoids, and fiber can compromise the bioavailability of carotenoids when consumed in excess.

To avoid the problem of correlated errors between repeated measurements, Kaaks ${ }^{3}$ suggested a triangulation between the dietary information obtained from the FFQ, the reference based in multiple $24 \mathrm{hR}$ or food record and biochemical markers.

This approach, known as the "triad" assumes that random errors $\varepsilon_{\mathrm{B}}, \varepsilon_{\mathrm{Q}}$ and $\varepsilon_{\mathrm{R}}$, present in all three measurements, are independent considering that each measurement shows a linear relationship with the true dietary intake (T). As such, errors from the use of biomarkers should not be correlated with errors from the dietary measurements, and their sources should thus be distinct 3 .

Although the triad method was described as early as the 1990s, its application in validation studies of FFQ is scarce 11,12,13. It is worth noting that validation of nutrient ingestion was prioritized in the studies in which this method was used 14,15. Therefore, the application of the triad method to validate food intake occurs very infrequently.

The objective of this study was to use the triad method to validate the intake of carotenoids, fruits and vegetables, as estimated by a food frequency questionnaire for adolescents from $\mathrm{Pi}$ racicaba, São Paulo, Brazil.

\section{Methods}

This study is part of a cohort study called Dietary Intake and Physical Activity as Determiners for Changes in Body Mass Index of a Cohort of Adolescents from Public Schools in the City of Piracicaba, São Paulo funded by the São Paulo State Research Foundation (FAPESP), nº. 02/9521-9. To calculate the sample size of cohort, the following information was considered: prevalence of overweight in a similar population (15\%); odds ratio
(OR) in population (1.6); type I error of 5\% and type II error of $20 \%$. The sampling procedure was simple random, stratified in series, conducted in two stages. More information on sample procedures was published in a previous study 16 .

Consent forms were distributed to all students at the $5^{\text {th }}$ and $8^{\text {th }}$ grade. A subset of 95 volunteer adolescents of both gender from a public school of Piracicaba participated of this methodological study. We used data from the baseline cohort conducted between August and October 2004. According to Cade et al. 17 the chosen sample should be representative of the principal sample (cohort) in the main study and should later be excluded for analysis. The choice of the school unit is justified by its central location, the heterogeneous characteristics of classes from 5 th through to 8th grade and because it contains students from diverse regions of the city.

Exclusion criteria included caloric consumption greater than $7,000 \mathrm{kcal}(\mathrm{n}=1) 18$, lack of full anthropometric data ( $\mathrm{n}=1)$ and lack of information on serum levels of $\beta$-carotene $(n=13)$. In the latter case, data on $\beta$-carotene levels were unavailable for subjects because their blood was not drawn due to failure to return a consent form signed by the parents or guardians. Thus, the final sample size was 80 subjects.

Adolescents were invited to participate in the study. Only adolescents who produced an informed and willing consent form signed by their parents or guardians were included in the sample. This research was approved by the Research Ethics Committee at the College of Public Health of the University of São Paulo.

\section{4-hour recall (24hR)}

After training by a research group, the $24 \mathrm{hR}$ was applied by staff at two different time points, with an interval of 30 to 45 days, on non-consecutive days, adopting the step by step approach proposed by Thompson \& Byers 19. Days selected for data collection were randomly distributed in order to capture intake variations on weekdays and weekends. Pictures of household measures were used for specific information on portion sizes. Photographic material was prepared by the research group responsible for the study.

\section{Food Frequency Questionnaire for Adolescents (FFQA)}

The usual intake was evaluated through the application by trained staff of the semiquantitative Food Frequency Questionnaire for Adolescents (FFQA). The FFQA was validated for energy and nutrients by Slater et al. 20 and for food groups 
by Voci et al. 21. Both of these previous studies produced satisfactory results.

The FFQA includes questions regarding the usual frequency of consumption of 94 food items during a six-month period. The portions presented in the FFQA represent the average consumption, in grams, of each food item. Food items are grouped according to physical characteristics and nutrient content per $100 \mathrm{~g}$. The possible answers in seven categories range from "never" to "twice a day". The construction of the questionnaire is described in greater detail by Slater et al. 20 .

The FFQA was administered in the form of a personal interview at a single point in time (the same period as the second $24 \mathrm{hR}$ ).

\section{Diet intake data processing}

Using custom-made measurement tables 21 and standards from previous studies, we converted the data collected from our tables into units of weight and volume, in order to calculate daily intake from the $24 \mathrm{hR}$. Preparations or foods cited that were not present in the tables or in existing documents were laboratory tested. The dietary intakes obtained from $24 \mathrm{hR}$ were calculated using NDS software (Nutrition Data System; School of Public Health, University of Minnesota, Minnesota, USA).

From the information obtained from the FFQA, the transformation of dietary intake frequency into a daily baseline was made possible using the Dietsys version 4.01 software (National Cancer Institute, Bethesda, USA). Data were entered in duplicate to eliminate any possible mistyping.

Total consumption of carotenoids was obtained from the sum of consumption of the following components: $\alpha$-carotene, $\beta$-carotene, cryptoxanthin, lutein and lycopene.

\section{Biochemical marker: serum $\beta$-carotene}

Blood samples were collected in the morning after an overnight fast. Analyses of serum levels of $\beta$-carotene were performed from a $10.0 \mathrm{~mL}$ blood sample. The sample collection was performed by a trained professional in a private location exclusively equipped for this purpose.

Blood was collected into vacutainer tubes containing ethylenediaminetetraacetic acidEDTA $(1.0 \mathrm{mg} / \mathrm{mL})$ as the anticoagulant and antioxidant. The samples were kept on ice and protected from light until the serum was collected. The following protease inhibitors were added to the serum: aprotinin $(10.0 \mu \mathrm{g} / \mathrm{mL})$, benzamidine $(10.0 \mu \mathrm{M})$ and phenylmethylsulphonyl fluoride
$(5.0 \mu \mathrm{M})$. The antioxidant 2,6-di-tert-butyl-p-hydroxytoluene-BHT $(100.0 \mu \mathrm{M})$ was also added to the serum. Plasma samples were stored at $-70^{\circ} \mathrm{C}$ in amber-colored glass tubes to preserve the antioxidants of present interest.

\section{Antioxidant measurements}

The plasma concentration of $\beta$-carotene was determined by high-pressure liquid chromatography (HPLC) using UV-Vis detectors (retinol) (PDA Shimadzu SPD-M 10A VP, Japan). Antioxidant extraction was performed away from light with methanol: hexane $(1: 3, \mathrm{v} / \mathrm{v})$, according to the protocol described by Moriel et al. 22. The hexane phase was evaporated, and the residue was dissolved in the mobile phase for the later determination of antioxidants. All samples were filtered through a $13 \mathrm{~mm}$ Millex polyethylene membrane with a $22.0 \mu \mathrm{m}$ pore size (Millipore São Paulo, Brazil) and then manually injected into the chromatograph $(20.0 \mu \mathrm{L})$. The $\beta$-carotene quantification in the samples was performed using external standards composed of $\beta$-carotene (Sigma Aldrich, St. Louis, USA) to construct a multilevel calibration curve in the Class-VC 10 program, LC-work station. We used the chromatography system LC-10 AT VP (Shimadzu, Japan), with a C18 column of 5 microns and 100 angstroms, measuring $250 \times 4.6 \mathrm{~mm}$ (Varian Microsorb - MV, Varian, Lake Forest, USA). The mobile phase was composed of methanol:acetonitri le:chloroform (35:35:30 v/v/v) containing 20mm lithium perchlorate and was run at a flow rate of $1 \mathrm{~mL} / \mathrm{min}$ for 20 minutes. All analyses were carried out in duplicate.

\section{Other data collection}

We computed each adolescent's age from his or her date of birth and the date when the questionnaire was applied. Height and weight were measured by trained research staff to the nearest $0.1 \mathrm{~cm}$ and $100 \mathrm{~g}$. We obtained these measures using standardized procedures. Anthropometry was performed without shoes or jackets. BMI was calculated as body weight $(\mathrm{kg})$ divided by height (m) squared. Based on the BMI, the adolescent's nutritional status was classified according to the system proposed by the World Health Organization (WHO) 23 by sex and age. The Tanner maturation stage was assessed by a validated selfrating of sexual maturity that uses categories/ illustrations for secondary sexual characteristics as development of breasts and pubic hair in girls and the genitals and pubic hair in boys 24. Data on anthropometry and sexual maturation were used only to characterize the sample. 


\section{Statistical analysis}

We initially used the Kolmogorov-Smirnov test to evaluate the adherence of the results to a normal distribution. The descriptive analysis included the calculation of the central tendency and dispersion for the information gathered through the $24 \mathrm{hR}$ and the FFQA. For the analysis, data referring to $\beta$-carotene dosage were transformed using logarithms.

We used a paired Student's t-test to compare differences among the average intake of carotenoids, fruits and vegetables between the FFQA and the two 24hR. The Pearson correlation coefficient was calculated to evaluate the linear association among intake of carotenoids, fruits and vegetables estimated by both methods of dietary intake evaluation (FFQA and 24hR). Considering that the majority of variables did not show significant differences between genders, we chose to analyze the data without subdividing by this variable.

We calculated the partial correlation coefficient to evaluate the association among the intake of carotenoids, fruits and vegetables obtained between the FFQA and R24h and the serum $\beta$-carotene levels. Because serum concentrations of carotenoids can be influenced by factors such as fats, cholesterol, fiber and BMI, we adjusted for these variables in order to account for possible interferences.

The triad method was used to estimate the validity coefficient between the unknown true intake and the intake estimated from the FFQA, $24 \mathrm{hR}$ and serum $\beta$-carotene (Figure 1 ). The validity coefficient can be estimated from the following equations:

$$
\begin{aligned}
& \mathrm{VC}_{\mathrm{QT}}=\sqrt{[(r Q R x r Q B) / r R B]}(1) \\
& \mathrm{VC}_{\mathrm{RT}}=\sqrt{[(r Q R x r R B) / r Q B]}(2) \\
& \mathrm{VC}_{\mathrm{BT}}=\sqrt{[(r Q B x r R B) / r Q R]}(3)
\end{aligned}
$$

where, $\mathrm{VC}_{\mathrm{QT}}, \mathrm{VC}_{\mathrm{RT}}$ and $\mathrm{VC}_{\mathrm{BT}}$ represent the validity coefficients between true dietary intake (T) and FFQA, $24 \mathrm{hR}$ and biomarker respectively; $\left[(r]_{Q B}\right)$ the correlation between the FFQ and biomarker; $\left[(r]_{\downarrow} R B\right)$ is the correlation between reference method ( $24 \mathrm{hR}$ or DD) and biomarker and $\left(r_{\downarrow} Q R\right)$ the correlation between FFQ and reference methods 3,25 .

Kaaks ${ }^{3}$ and Ocké \& Kaaks 25 suggested that the estimate be interpreted as the upper limit, and that the correlation between the biomarker and the two methods of evaluating consumption be interpreted as the lower limit of the true validity coefficient $\left(r_{\downarrow} Q R\right)$ was estimated from the Pearson correlation coefficient, while the partial correlation coefficient was used for the estimate of $\left[(r]_{Q B}\right)$ and $\left[(r]_{\downarrow} R B\right)$. This method has been described in further detail by Ocké \& Kaaks 25.

The $95 \%$ confidence intervals $(95 \% \mathrm{CI})$ of the validity coefficients were calculated using the "bootstrap" method, in which 1,000 samples of equal size $(n=80)$ are generated randomly and with substitution 25 . The $95 \%$ CI were obtained from the 2.5 and 97.5 percentiles in the distribution of all the coefficients obtained in the 1,000 bootstrap samples. A program was written in MATLAB 7.0 (The MathWorks, Natick, USA) to calculate the $95 \%$ CI.

Significance was set at the level of 5\%, and all the analyses were performed using the SPSS software, version 15.0 (SPSS Inc., Chicago, USA).

\section{Results}

Of the 80 adolescents who participated in the study, $72 \%$ were female. The average age was 13.0 \pm 1.1 years. Regarding sexual maturity, only $7 \%$ were considered prepubescent. Excess weight was present in $26 \%$ of the adolescents, with $19 \%$ overweight and $7 \%$ obese (data not shown in tables).

The intake of carotenoids, fruits and vegetables evaluated by the FFQA and $24 \mathrm{hR}$ is presented in Table 1. Comparing the estimated intakes obtained by the FFQ and the $24 \mathrm{hR}$, we observed that only the intake of carotenoids was greater when assessed by the $24 \mathrm{hR}(\mathrm{p}=0.02)$. Consumption of vegetables $(p<0.01)$ and fruits/vegetables $(p<0.01)$ was statistically greater when assessed by the FFQA. Regarding fruits, there was no significant difference between the estimated intake obtained from the FFQA and the $24 \mathrm{hR}$.

Table 2 presents the Pearson correlation coefficients between intake values from the FFQA and the $24 \mathrm{hR}$ and their confidence intervals. The values vary from 0.208 (carotenoids) to 0.373 (vegetables), and all are statistically significant $(\mathrm{p}<0.05)$.

The partial correlation coefficients obtained between the estimated intake of carotenoids, fruits and vegetables and serum $\beta$-carotene levels are presented in Table 3.

It is worth noting that, in general, the partial correlation coefficients were greater for the FFQA. The only exception was the carotenoids, which presented a slightly greater value in the 24hR than for the FFQA. The coefficients obtained between the $\beta$-carotene serum levels and the intake of fruits/vegetables was high for the FFQA $(r=0.235)$ as well as for the $24 \mathrm{hR}(r=0.137)$. 
Figure 1

Illustration of the triad method used to estimate the validity coefficient between the true dietary intake and the intakes estimated by the 24-hour recall (24hR), Food Frequency Questionnaire for Adolescents (FFQA) and biomarkers *.
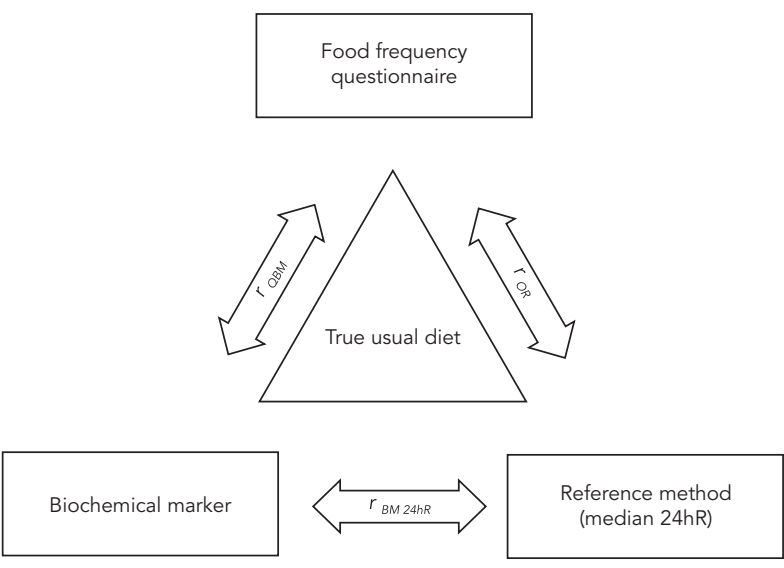

* Adapted from Kabagambe et al. 15.

Table 1

Intake values of carotenoids, fruits and vegetables obtained from the Food Frequency Questionnaire for Adolescents (FFQA) and the 24-hour recall (24hR) among adolescents. Piracicaba, São Paulo State, Brazil, 2004.

\begin{tabular}{|c|c|c|c|c|c|c|c|}
\hline \multirow[t]{2}{*}{ Variables } & \multicolumn{3}{|c|}{ FFQA $(n=80)$} & \multicolumn{3}{|c|}{$24 \mathrm{hR}(\mathrm{n}=80)$} & \multirow[t]{2}{*}{$\mathrm{p}$-value * } \\
\hline & Average & $\begin{array}{l}\text { Standard } \\
\text { deviation }\end{array}$ & Median & Average & $\begin{array}{l}\text { Standard } \\
\text { deviation }\end{array}$ & Median & \\
\hline Carotenoids ( $\mu \mathrm{g} /$ day) & $4,150.6$ & $2,773.8$ & $3,433.1$ & $6,910.8$ & $12,380.2$ & 4396.6 & 0.02 \\
\hline Fruits (g/day) & 284.0 & 122.58 & 169.4 & 97.7 & 63.2 & 98.6 & 0.49 \\
\hline Vegetables (g/day) & 104.3 & 69.6 & 79.2 & 66.8 & 62.9 & 52.1 & $<0.01$ \\
\hline Fruits/Vegetables (g/day) & 306.8 & 137.5 & 276.2 & 94.4 & 84.7 & 68.8 & 0.01 \\
\hline
\end{tabular}

* Paired Student $t$ test.

Table 2

Pearson correlation coefficients and $95 \%$ confidence intervals $(95 \% \mathrm{Cl})$ among the intake of carotenoids, fruits and vegetables estimated by the Food Frequency Questionnaire for Adolescents (FFQA) and the 24-hour recall (24hR). Piracicaba, São Paulo State, Brazil, 2004.

\begin{tabular}{lll}
\hline Variables & Pearson correlation coefficients * & $95 \% \mathrm{Cl}$ ** \\
\hline Carotenoids ( $\mathrm{gg} /$ day) & 0.208 & $0.207 ; 0.209$ \\
Fruits (g/day) & 0.219 & $0.218 ; 0.220$ \\
Vegetables (g/day) & 0.373 & $0.372 ; 0.374$ \\
Fruits/Vegetables (g/day) & 0.244 & $0.243 ; 0.245$ \\
\hline
\end{tabular}

* All values are statistically significant $(p<0.05)$;

** Confidence intervals estimated by the bootstrap method. 
Partial correlation coefficients * among the intake of carotenoids, fruits and vegetables and serum $\beta$-carotene levels. Piracicaba, São Paulo State, Brazil, 2004.

\begin{tabular}{lll}
\hline Evaluation method & $\beta$-carotene serum levels & $95 \% \mathrm{Cl}$ ** \\
\hline FFQA $(\mathrm{n}=80)$ & & $0.092 ; 0.094$ \\
Carotenoids ( $\mu \mathrm{g} /$ day) & 0.093 & $0.216 ; 0.218$ \\
Fruits (g/day) & 0.217 & $0.146 ; 0.148$ \\
Vegetables (g/day) & 0.147 & $0.234 ; 0.236$ \\
Fruits/Vegetables (g/day) & 0.235 & $0.094 ; 0.096$ \\
24 hR ( $=80$ ) & & $0.129 ; 0.131$ \\
Carotenoids ( $\mathrm{gg} /$ day) & 0.095 & $0.071 ; 0.073$ \\
Fruits (g/day) & 0.130 & $0.136 ; 0.138$ \\
Vegetables (g/day) & 0.072 & 0.137 \\
Fruits/Vegetables (g/day) & & \\
\hline
\end{tabular}

95\% Cl: 95\% confidence intervals; FFQA: Food Frequency Questionnaire for Adolescents; 24hR: 24-hour recall.

* Partial correlation coefficients adjusted for BMI, total fat, total cholesterol and fiber;

** Confidence intervals estimated using the bootstrap method.

Table 4 presents the validity coefficients for the FFQA, 24hR and the $\beta$-carotene serum levels (biochemical marker).

The validity coefficients varied from 0.451 to 0.873 for the FFQA, from 0.362 to 0.461 for the $24 \mathrm{hR}$, and from 0.168 and 0.363 for the serum $\beta$-carotene. The observed validity coefficients for the estimated intake of fruits, vegetables and fruits/vegetables from the FFQA was greater when compared with the values obtained from the $24 \mathrm{hR}$ and the $\beta$-carotene serum levels. Validity coefficients obtained from the vegetable group showed the highest variation of amplitude, representing the greatest validity coefficients for the FFQA and the lowest value for serum $\beta$-carotene values.

\section{Discussion}

The FFQ is one of the most commonly used instruments in the majority of large-sample studies in nutritional epidemiology. The FFQA was previously validated for nutrients by Slater et al. 20 and calibrated by Voci et al. 26. These studies proved that the FFQA is a reasonably accurate tool. The validation of this same instrument for food groups was conducted by Voci et al. ${ }^{21}$ using the same calibration sample as that used for validity testing for nutrients and in the same sample as that used in the present study. The number of individuals that constituted the sample in the study of Voci et al. 21 was greater than the number used in the present work, although the validation method did not use a biomarker. In this study conduced by Voci et al. 21 the adjusted correlation coefficient for fruits, vegetables and naturals juice were $0.75,0.68$, and 0.62 respectively.

The validation method used in this study has also been utilized by other authors. Bhakta et al. 27 used biomarkers and the triad method to investigate the relative validity of the FFQ in estimating the intake of phytoestrogens in Asian women. Multiple $24 \mathrm{hR}$ were used (average of 13 evaluations) as a reference method. The bootstrap sampling method was also used.

In a study performed in Costa Rica, Kabagambe et al. 15 also used the triad method and estimated 1,000 samples of equal size using the bootstrap method to estimate confidence intervals for the validity coefficients. However, the authors also adjusted the correlation coefficients using the quotient of the variances (correction by intrapersonal variability).

We can compare the correlation coefficients obtained between the two methods of dietary evaluation with those presented by Andersen et al. 11 between FFQ and records with food weights (varying from 0.33 to 0.45 all significant), which were unadjusted for intrapersonal variability and for energy; it is apparent that, except for the values obtained for vegetables, all correlation coefficients obtained using the two methods of dietary evaluation were smaller. Regarding calculated coefficients for serum $\beta$-carotene and the dietary variables of the FFQ, Andersen et al. 11 obtained greater correlations with their methods; indeed, only the correlation coefficients for fruits were equal to those presented in this study. 
Validity coefficients and $95 \%$ confidence intervals $(95 \% \mathrm{Cl})$ for the intake of carotenoids, fruits and vegetables estimated by the Food Frequency Questionnaire for Adolescents (FFQA), the 24-hour recall (24hR), and the $\beta$-carotene serum levels as a biomarker for carotenoids, fruits and vegetables. Piracicaba, São Paulo State, Brazil, 2004.

\begin{tabular}{|c|c|c|c|c|c|c|}
\hline \multirow[t]{2}{*}{ Variables } & \multicolumn{2}{|c|}{ FFQA } & \multicolumn{2}{|c|}{$24 \mathrm{hR}$} & \multicolumn{2}{|c|}{ Serum $\beta$-carotene } \\
\hline & $\begin{array}{c}\text { Validity } \\
\text { coefficients }\end{array}$ & $95 \% \mathrm{Cl}$ * & $\begin{array}{c}\text { Validity } \\
\text { coefficients }\end{array}$ & $95 \% \mathrm{Cl}$ * & $\begin{array}{c}\text { Validity } \\
\text { coefficients }\end{array}$ & $95 \% \mathrm{Cl}$ * \\
\hline Carotenoids & 0.451 & $0.449 ; 0.453$ & 0.461 & $0.458 ; 0.464$ & 0.206 & $0.205 ; 0.207$ \\
\hline Fruits & 0.605 & $0.603 ; 0.606$ & 0.362 & $0.361 ; 0.363$ & 0.359 & $0.358 ; 0.360$ \\
\hline Vegetables & 0.873 & $0.868 ; 0.876$ & 0.427 & $0.426 ; 0.429$ & 0.168 & $0.167 ; 0.169$ \\
\hline Fruits/Vegetables & 0.647 & $0.645 ; 0.648$ & 0.377 & $0.376 ; 0.378$ & 0.363 & $0.362 ; 0.364$ \\
\hline
\end{tabular}

* $95 \%$ confidence intervals estimated using the bootstrap method.

Bhakta et al. 27 observed that the vegetable group (including prepared foods with vegetables) and the bread group were responsible for about $95 \%$ of intake of all phytoestrogens. In addition, the correlation between serum phytoestrogens and dietary variables was lower for the FFQ than for the $24 \mathrm{hR}$ in their study. However, in the present study, the coefficients obtained for the FFQ were greater than for the $24 \mathrm{hR}$. Bhakta et al. 27 also claim that FFQ possibly overestimated the consumption of some food groups, namely the quantity of phytoestrogens supplied in the bread, fruit and fruit juice food groups. This overestimation may be the result of large portion size and a greater frequency of consumption.

According to Willett 28, the problem of overestimation in the frequency of intake occurs particularly for the fruit group when it is estimated using the FFQ, while the reference method tends to show an underestimation. The overestimation by the FFQ in relation to the reference method was also reported by Brunner et al. 29 and Kabagambe et al. 15 .

The correlation coefficients obtained by Kabagambe et al. 15 for the two dietary methods varied from 0.44 (lycopene) to 0.57 (zeaxantine and lutein). The partial correlation coefficients between the serum biomarkers and the $24 \mathrm{hR}$ varied from 0.35 (beta-carotene) to 0.45 (lycopene). For the FFQ, the partial correlation coefficients varied from 0.26 (lycopene) to 0.58 (beta-cryptoxanthin).

The correlation coefficients calculated between dietary carotenes adjusted for energy and serum $\beta$-carotenes showed that the intake of carotenes was better estimated by the FFQ than by the reference method in the Brunner et al. 29 study. In the present study, the calculated coefficients between the biochemical marker and the dietary carotenoids were practically equal in both methods (close to 0.09). In the study by Brunner et al. 29 , the correlation between serum $\beta$-carotene and dietary carotene was approximately 0.2 . It varied from 0.35 in males to 0.37 in females in both methods, which are values greater that the ones in the present study.

According to Kaaks 3 the correlation coefficients obtained between biomarkers and the estimated intake values from the FFQ are generally smaller that 0.40 due to interference. This interference may be exerted by factors that disrupt the absorption of these nutrients, as well as metabolism and physiological regulation; thus, facilitating random variability not related with true dietary intake. It is possible that the results presented in the present work have been influenced by these interferences, since the partial correlation coefficients were very low.

Regarding the validity coefficients observed by Andersen et al. 11, the values obtained varied from 0.07 to 0.26 between the serum $\beta$-carotene and the total intake of fruits and vegetables. While the greatest validity coefficient observed by Andersen et al. 11 was for the intake of vegetables obtained by the reference method and serum $\beta$-carotene, the present study revealed that the validity coefficient was the greatest between the biomarker and vegetable intake as assessed by the FFQA. This result was unexpected, since greater accuracy was expected for the reference method. These data could be explained by the fact that the FFQA shows fruits and vegetables rich in total carotenoids (such as lycopene, alpha-carotene, beta-carotene and xanthines). In addition, the intake of vegetables was greater when assessed by the FFQA. Other authors have presented correlations between 0.31 to 0.45 for the intake of these food groups and serum $\beta$-carotene 9,30,31.

Similar to what was observed by Andersen et al. 11 the validity coefficients for the biomarker 
were lower than those observed for the dietary variables. Bhakta et al. 27 also found that validity coefficients for biomarkers were lower than those obtained for the FFQ and the $24 \mathrm{hR}$.

Regarding the calculated validity coefficient for the dietary intake methods, Ocké \& Kaaks 25 obtained strong results for the FFQ. The validity coefficient observed by Kabagambe et al. 15 for serum $\beta$-carotene and dietary variables was 0.50 for the biomarker, 0.71 for the $24 \mathrm{hR}$ and 0.76 for the FFQ.

Kabagambe et al. 15 obtained strong validity coefficients using the FFQ, suggesting that it is a valid method for dietary evaluation. For beta-cryptoxanthin and lycopene, validity coefficient values by FFQ were greater or comparable to those obtained by the biomarker, suggesting that the FFQ and the biomarker are comparable. The Ocke \& Kaaks 25 study used a sample size of 61 individuals and produced validity coefficient values of $0.44,0.58$ and 0.32 for the FFQ, $24 \mathrm{hR}$ and biomarker, respectively. These results demonstrate that the biomarker coefficient was the lowest in those studies.

In another study conducted by Daures et al. 32 (with a sample size of 87 individuals), the validity coefficient values observed were $0.39,0.52$ and 0.85 for the FFQ, diet records and serum $\beta$-carotene, respectively.

The discrepancies between the results in the cited studies could be consequences of differences in reference methods used, different structures of the applied FFQ, differences in sample size or differences in the populations being studied 15,27

In addition to accuracy, another aspect to be discussed in validation studies is the level of precision of the estimate. In general, this is expressed by the $95 \% \mathrm{CI}$ and is not simply an attempt to estimate the coefficient without bias. The technique most often used to calculate the $95 \% \mathrm{CI}$ for the validity coefficient is the bootstrap technique 14,15,16. According to Hair et al. 33 bootstrapping is a non-parametric re-sampling technique that uses the original data to generate hundreds of samples with the same " $n$ " as the original sample (80 adolescents in the present study). Thus, as observed in this study, the lower the generated bivariable correlation between studied variables, the greater the 95\%CI (for example, the carotenoids).

\section{Methodological limitations}

\section{Daily fluctuations}

Some of the partial correlations found in this study are similar to those found in the literature 11,12. However, contrary to what was observed in the referenced studies, we did not find any negative correlations. This situation would prevent the estimation of a validity coefficient, since this method requires the application of a square root.

It is possible that the validity coefficient presented in this study is also overestimated as a consequence of probable correlation between the evaluation methods of dietary intake.

In contrast, we observed very low correlation values, probably due to daily fluctuations in the diets of the adolescents. One plausible explanation for these observations may relate to the rural characteristics of the city of Piracicaba; the city offers many options for fruit consumption, especially during harvest time. Increasing the sample size could diminish or control these fluctuations.

Several authors have noted that serum levels are also influenced by day-to-day fluctuations and individual variability $34,35,36,37$. Therefore, carotenoid levels from a single blood sample cannot accurately determine the usual intake of these nutrients. This type of error can attenuate the correlations observed between intake and biomarker.

\section{Theoretical assumptions}

Validation through comparison of imperfect methods requires that some statistical estimates be assumed, such as the independence from the random errors between all three measures of validations 38 .

Most studies present results on relative validation, using $24 \mathrm{hR}$ as the reference method. This fact has been constituted as an important limitation, since the types of errors can be correlated, so they are not independent errors 39 . Another recent study conducted with schoolchildren presents validation results of a questionnaire on the day prior (QUADA-3) in relation to direct observation conducted by trained researchers, avoiding the same sources of errors. However, the instrument represents the present day and carries out a qualitative assessment of the consumption of individuals aged between 6 and 11 years 40 .

However, Kaaks \& Ferrari 38 assert that violation of the assumption of independence of random errors, implicit in the correlations between pairs of instruments, is due to the fact that each 
of the instruments used describes the same latent variable. In this sense, the choice of biochemical markers is of interest in validation studies, since this will present a true independence from random errors between the methods of dietary measurement 25 .

According to Kaaks 3, when the assumption of independence between the errors of the two methods of dietary evaluation is violated, the correlations among the FFQ, the $24 \mathrm{hR}$ and the true diet are probably overestimated. Generally, the correlations between the FFQ and biomarkers are low. For this reason, it is advisable to undertake the triangular analysis incorporating dietary reference measurements (24hR or diet diaries).

\section{Values greater than 1.0 and negative coefficients}

Bhakta et al. 27 point to the existence of technical difficulties in their study, with one of the difficulties being validity coefficient values greater than 1.0 (Heywood cases).

Negative or very low values can generate validity coefficients greater than 1 . In this case, values greater than 1 are commonly known as a "Heywood case", which can occur when the product of the bi-variable correlation $\left(\mathrm{r}_{\mathrm{QR}}=0.32\right.$ $\left.* r_{\mathrm{RB}}=0.27\right)$ is greater than the third $\left(\mathrm{r}_{\mathrm{RB}}=0.05\right)$. In this case, validation coefficients are commonly accepted 3,25 .
One other explanation for the occurrence of the "Heywood case" is primarily due to the violation of one or more assumptions in the method of triads, as a result of using measurement instruments that possess the same source of error 3 .

In the present study, we did not observe negative values or values greater than 1.0.

\section{Final remarks}

Kabagambe et al. 15 concluded that the performance of the biomarkers used in their study was not better than that obtained with the FFQ. Based on this finding, they determined that biomarkers should be used as an additional method of dietary intake evaluation and not as a substitute.

However, Yeum et al. 7 and Broekmanns et al. 6 claim that due to errors associated with traditional tools, controlled diet studies suggest that the plasma $\beta$-carotene is a potential biochemical marker for the consumption of fruits and vegetables.

\section{Conclusion}

From the validity coefficients, it was possible to observe that the FFQA has good accuracy in measuring the consumption of carotenoids, fruits and vegetables in this population group.

\section{Resumo}

O objetivo do estudo foi validar a ingestão de carotenóides, frutas e hortaliças estimada pelo Questionário de Frequência Alimentar para Adolescentes (QFAA) utilizando o método das tríades. Foram coletadas amostras sanguíneas de 80 adolescentes de uma escola de Ensino Fundamental para análise do $\beta$-caroteno plasmático. Coeficientes de correlação (r) parciais foram obtidos entre a ingestão de carotenóides, frutas e hortaliças e o $\beta$-caroteno plasmático. Os coeficientes de validade foram estimados a partir do método das tríades. O QFA apresentou valores de r parcial superiores ao recordatório alimentar de 24 horas (R24h), exceto para carotenóides. O grupo das frutas/hortali- ças apresentou os maiores valores de $r$ parciais tanto para o questionário de frequência alimentar (QFA) $(r=0,235)$ quanto para $R 24 h(r=0,137)$. O maior coeficiente de validade foi o do grupo de hortaliças avaliado pelo QFA ( $r=0,873)$. Os valores de coeficiente de validade observados para o QFA foram em média superiores aos obtidos para R24h e $\beta$-caroteno plasmático. O QFAA é um instrumento com boa acurácia para estimar o consumo de carotenóides, frutas e hortaliças nesse grupo populacional.

Consumo de Alimentos; Questionário; Adolescente; Estudos de Validação 


\section{Contributors}

S. M. Voci was involved in data collection, data interpretation and participated in writing the manuscript. B. Slater participated in the project design, coordinated the data collection and participated in writing the manuscript. C. C. Enes was responsible for the statistical analyses, participated in data interpretation and wrote the manuscript. R. V. M. López helped in the statistical analysis and participated in writing the manuscript. N. R. T. Damasceno contributed with blood sample analysis and reviewed the manuscript. All of the authors critically revised the contents of the paper and approved the final version.

\section{References}

1. Klerk NH, English DR, Armstrong BK. A review of the effects of random measurement error on relative risk estimates in epidemiological studies. Int J Epidemiol 1989; 18:705-12

2. Freedman LS, Schatzkin A, Wax Y. The impact of dietary measurement error on planning sample size required in a cohort study. Am J Epidemiol 1990; 132:1185-95.

3. Kaaks RJ. Biochemical markers as additional measurements in studies of the accuracy of dietary questionnaire measurements: conceptual issues. Am J Clin Nutr 1997; 65(4 Suppl):1232S-9S.

4. Potischman N. Biologic and methodologic issues for nutritional biomarkers. J Nutr 2003; 133 Suppl 3:875S-80S

5. Hunter D. Biochemical indicators of dietary intake. In: Willett WC, editor. Nutritional epidemiology. 2nd Ed. New York: Oxford University Press; 1998. p. 174-243.

6. Broekmanns WMR, Klöpping-Ketelaars IAA, Schuurman CRWC, Verhagen H, van den Berg H, Kok FJ, et al. Fruits and vegetables increase plasma carotenoids and vitamins and decrease homocysteine in human subjects. J Nutr 2000; 130: 1578-83.

7. Yeum K, Booth SL, Sadowski JA, Jackson A, Tang G, Krinsky NI, et al. Human plasma carotenoid response to the ingestion of controlled diet high in fruits and vegetables. Am J Clin Nutr 1996; 64: 594-602.

\section{Acknowlegdgments}

To the São Paulo State Research Foundation (FAPESP 02/9521-9) for sponsorship of the study.
8. Martini MC, Campbell DR, Gross MD, Grandits GA, Potter JD, Slavin JL. Plasma carotenoids as biomarkers of vegetable intake: the University of Minnessota Cancer Prevention Research Unit Feeding Studies. Cancer Epidemiol Biomarkers Prev 1995; 4:491-6.

9. Campbell DR, Gross MD, Martini MC, Grandits GA, Slavin JL, Potter JD. Plasma carotenoids as biomarkers of vegetable and fruit intake. Cancer Epidemiol Biomarkers Prev 1994; 3:493-500.

10. Olson JA. Carotenoids. In: Shils ME, Olson JA, Shike M, Ross AC, editors. Modern nutrition in health and diseases. Philadelphia: Lippincott Williams \& Wilkins; 1999. p. 525-41.

11. Andersen LF, Veierod MB, Johansson L, Sakhi A, Solvoll K, Drevon CA. Evaluation of three dietary assessment methods and serum biomarkers as measures of fruit and vegetable intake, using the method of triads. Br J Nutr 2005; 93:519-27.

12. McNaughton SA, Marks GC, Gaffney P, Williams G, Green A. Validation of a food-frequency questionnaire assessment of carotenoid and vitamin E intake using weighed food records and plasma biomarkers: the method of triads model. Eur J Clin Nutr 2005; 59:211-8.

13. Verkleij-Hagoort AC, Vries JHM, Stegers MPG, Lindemans J, Ursem NTC, Steegers-Theunissen RPM. Validation of the assessment of folate and vitamin B12 intake in women of reproductive age: the method of triads. Eur J Clin Nutr 2007; 61:610-5. 
14. Pufulete M, Emery PW, Nelson M, Sanders TAB. Validation of a short food frequency questionnaire to assess folate intake. Br J Nutr 2002; 87:383-90.

15. Kabagambe EK, Baylin A, Allan DA, Siles X, Spiegelman D, Campos H. Application of the method of triads to evaluate the performance of food frequency questionnaires and biomarkers as indicators of long-term dietary intake. Am J Epidemiol 2001; 154:1126-35.

16. Toral N, Slater B, Silva MV. Food consumption and overweight in adolescents from Piracicaba, São Paulo, Brazil. Rev Nutr 2007; 20:449-59.

17. Cade J, Thompson R, Burley V, Warm D. Development, validation and utilization of food-frequency questionnaires-a review. Public Health Nutr 2002; 5:567-87.

18. Ludwig DS, Peterson KE, Gortmaker SL. Relation between consumption of sugar-sweetened drinks and childhood obesity: a prospective, observational analysis. Lancet 2001; 357:505-8.

19. Thompson FE, Byers T. Dietary assessment resource manual. J Nutr 1994; 124(11 Suppl): 2245S$317 \mathrm{~S}$.

20. Slater B, Fisberg RM, Philippi ST, Latorre MRO. Validation of a semi-quantitative adolescents food frequency questionnaire applied at a public school in São Paulo, Brazil. Eur J Clin Nutr 2003; 57: 629-35.

21. Voci SM, Enes CC, Slater B. Validação do Questionário de Freqüência Alimentar para Adolescentes (QFAA) por grupos de alimentos em uma população de escolares. Rev Bras Epidemiol 2008; 11:561-72.

22. Moriel P, Andrade PM, Rodrigues D, Bertolani MC, Abdalla DSP. Antioxidantes e oxidabilidade da LDL em pacientes hiperlipidêmicos. Rev Bras Anal Clin 1998; 30:176-80.

23. Onis M, Onyango AW, Borghi E, Siyam A, Nishida C, Siekmann J. Development of a WHO growth reference for school-aged children and adolescents. Bull World Health Organ 2007; 85:660-7.

24. Tanner JM. Growth at adolescence. 2nd Ed. Oxford: Blackwell Scientific Publications; 1962.

25. Ocké M, Kaaks R. Biochemical markers as additional measurements in dietary validity studies: application of the method of triads with examples from the European Prospective Investigation into Cancer and Nutrition. Am J Clin Nutr 1997; 65(4 Suppl):1240S-5S.

26. Voci SM, Slater B, Silva MV, Marchioni DML, Latorre MRDO. Estudo de calibração do Questionário de Freqüência Alimentar para Adolescentes - QFAA. Ciênc Saúde Coletiva; in press.

27. Bhakta D, Silva IS, Higgins C, Sevak L, KassamKhamis T, Mangtani P, et al. A semiquantitative food frequency questionnaire is a valid indicator of the usual intake of phytoestrogens by South Asian women in the UK relative to multiple 24 -h dietary recalls and multiple plasma samples. J Nutr 2005; 135:116-23.
28. Willett WC. Nutritional epidemiology. 2nd Ed. New York: Oxford University Press; 1998.

29. Brunner E, Stallone D, Juneja M, Bingham S, Marmot M. Dietary assessment in Whitehall II: comparison of $7 \mathrm{~d}$ diet diary and food-frequency questionnaire and validity against biomarkers. Br J Nutr 2001; 86:405-14.

30. Resnicow K, Odom E, Wang T, Dudley WN, Mitchell D, Vaughan R, et al. Validation of three food frequency questionnaires and 24-hour recalls with serum carotenoid levels in a sample of African-American adults. Am J Epidemiol 2000; 152: 1072-80.

31. Block G, Norkus E, Hides M, Mandel S, Helzlsouer K. Which plasma antioxidants are most related to fruit and vegetable consumption. Am J Epidemiol 2001; 154:1113-8.

32. Daurès JP, Gerber M, Scali J, Astre C, Bonifacj C, Kaaks R. Validation of a food-frequency questionnaire using multiple-day records and biochemical markers: application of the triads method. J Epidemiol Biostat 2000; 5:109-15.

33. Hair Jr. JF, Anderson RE, Tatham RL, Black WC. Análise multivariada de dados. $5 \underline{a}$ Ed. Porto Alegre: Bookmann; 2005.

34. Tangney CC, Shekelle RB, Raynor W, Gale M, Betz EP. Intra- and interindividual variation in measurements of beta-carotene, retinol, and tocopherols in diet and plasma. Am J Clin Nutr 1987; 45:764-9.

35. Olmedilla B, Granada F, Blanco I, Rojas-Hidalgo E. Seasonal and sex-related variations in six serum carotenoids, retinol, and alpha-tocopherol. Am J Clin Nutr 1994; 60:106-10.

36. Cooney RV, Franke AA, Hankin JH, Custer LJ, Wilkens LR, Harwood PJ, et al. Seasonal variation in plasma micronutrients and antioxidants. Cancer Epidemiol Biomarkers Prev 1995; 4:207-15.

37. Scott KJ, Thurnham DI, Hart DJ, Bingham SA, Day $\mathrm{K}$. The correlation between the intake of lutein, lycopene and beta-carotene from vegetables and fruits, and blood plasma concentrations in a group of women aged 50-65 years in UK. Br J Nutr 1996; 75:409-18.

38. Kaaks R, Ferrari P. Dietary intake assessments in epidemiology: can we know what we are measuring? Ann Epidemiol 2006; 16:377-80.

39. Zanolla AF, Olinto MTA, Henn RL, Wahrlich V, Anjos LA. Avaliação de reprodutibilidade e validade de um questionário de freqüência alimentar em adultos residentes em Porto Alegre, Rio Grande do Sul, Brasil. Cad Saúde Pública 2009; 25:840-8.

40. Assis MAA, Benedet J, Kerpel R, Vasconcelos FAG, Di Pietro PF, Kupek E. Validação da terceira versão do Questionário Alimentar do Dia Anterior (QUADA-3) para escolares de 6 a 11 anos. Cad Saúde Pública 2009; 25:1816-26.

Submitted on 02/Sep/2009

Final version resubmitted on 09/Dec/2009 Approved on 01/Mar/2010 